\title{
lessons from Iranian hot cities for future hot cities
}

\author{
Nasim IRANMANESH, Islamic Azad university of Tehran, Iran
}

\begin{abstract}
Iran is an ancient country with an old civilization. Most parts of this country have been located in hot and dry region. Many cities of Iran suffer from harsh climate and water scarcity both. But we notice a rich urban planning and architecture in these cities which were adapted with this hard situation. We can survey this adaptation in many aspects of traditional urban planning and architecture in Iran. They could build some building with a good energy saving and prepared some spaces with suitable condition for living. Desert has a harsh climate with hot days and cold nights but Iranians build their houses in such a way to keep warm temperature during nights in their walls and then it had cold walls in days to reduce the temperature of the rooms. Besides they divided their homes to two parts, one part for winter and the second for summer. In summer part they used wind tower to catch and bring the wind into rooms. These houses had central yards which contained pool and plants to reduce the temperature of hot days as well. Briefly, there is a special climatic design in traditional houses of hot cities of Iran. Urban planning of these cities respected some features to reduce the effect hot climate as well. For example, there was a dense urban fabric in these cities with narrow lanes. Also, they could achieve the problem of limitation of water by some intellectual technology which called Qanat. Locating of most of the urban elements of cities obeyed from these Qanats. This Qanat provided drinkable water of city and citizens used water by some traditional hydraulic structures such as water reservoir or baths or ice house and so on. Nowadays sustainable design in architecture and urban planning is an important and essential paradigm. This paradigm emphasized on adapting with nature instead destroying it. Traditional architecture and urban planning of these Iranian cities of hot and dry climate contains a lot of features which can be useful for urban development of future hot cities which will be developed by sustainable urban planning paradigm. This paper reviews some features in traditional urban planning and architecture as some useful lessons for recent and future hot cities. Indeed, there are some aspects in these cities which can lead us a more sustainability in urban planning specially for hot cities.
\end{abstract}

Keywords

Traditional architecture and urban planning, sustainable development, historical cities of Iran

\section{Introduction:}

Many cities of Iran suffer from harsh climate and water scarcity. But there are a rich urban planning and architecture in Iranian cities which were adapted with this hard situation.

This paper reviews some features in traditional urban planning and architecture as lessons for recent and future hot cities. There are some aspects in these cities which can lead us a more sustainability in urban planning.

This paper has been divided in two sections, urban planning scale and architectural scale. Before that there is a brief explanation about the climatic regions of Iran.

\section{Climatic regions of Iran}

Iran is a special country which have four climatic regions: mild and humid region, cold region, hot and humid region and hot and dry region. Most parts of this country (\%75) has been located in hot 
and dry region. Every climatic region in Iran has a specific vernacular urban planning and architecture and, in this paper, I just discuss about the features of urban planning and architecture of hot and dry region.

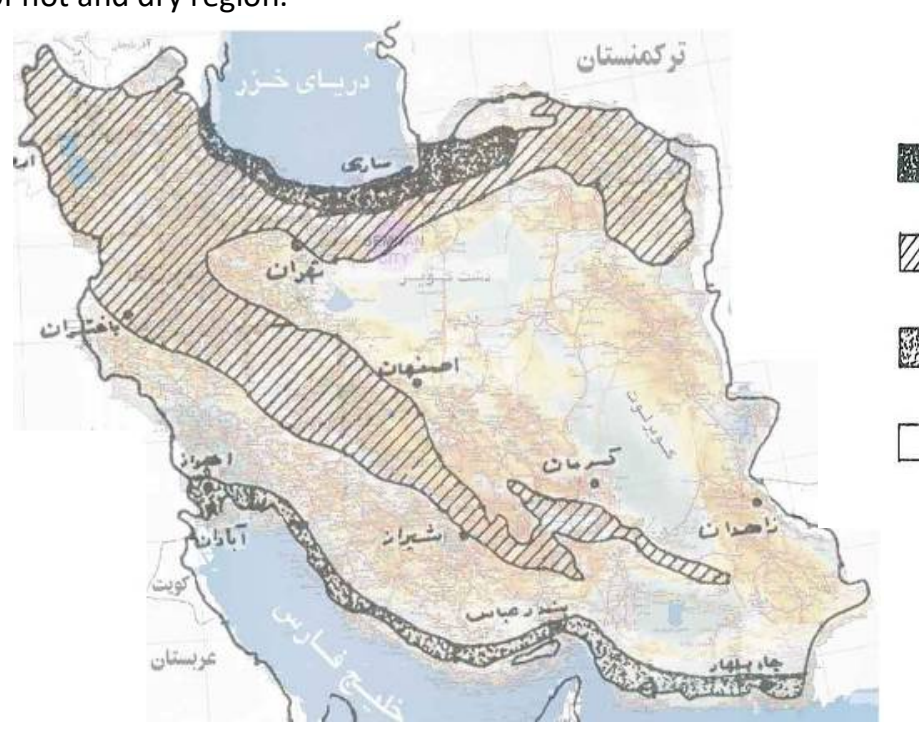

\begin{tabular}{lll}
\cline { 2 - 2 } & mild \& humid region \\
cold region \\
hot \& humid region \\
dry \& hot region
\end{tabular}

Figure 1- four climatic regions of Iran

\section{2- The features of urban planning in hot and dry region:}

In this region the fabric of settlement is impact and buildings have been attached to each other to mitigate the external walls according its volumes. The density and compacting in houses caused minimizing the rate of thermal exchanging through the external walls of buildings either in summer or in winter. So, in summer the heating of sun couldn't penetrate inside the building and in winter the heat of rooms couldn't go out as well. The energy saving was increased efficiently in this way. Usually buildings were constructed in very compact urban fabric, in this way more shadow were created on external surfaces. Due to the compaction of houses in urban fabric, the delay in time of heat transferring was optimized so during the day the heat of sun couldn't arrive inside the house quickly but after a long delay in the beginning of night the heat entered inside when the sun had gone and the weather in cold.

Figure 2 is a picture from urban fabric of Yazd city one of the hot cities in Iran. This is an ancient city in spite of severe water scarce in that region.

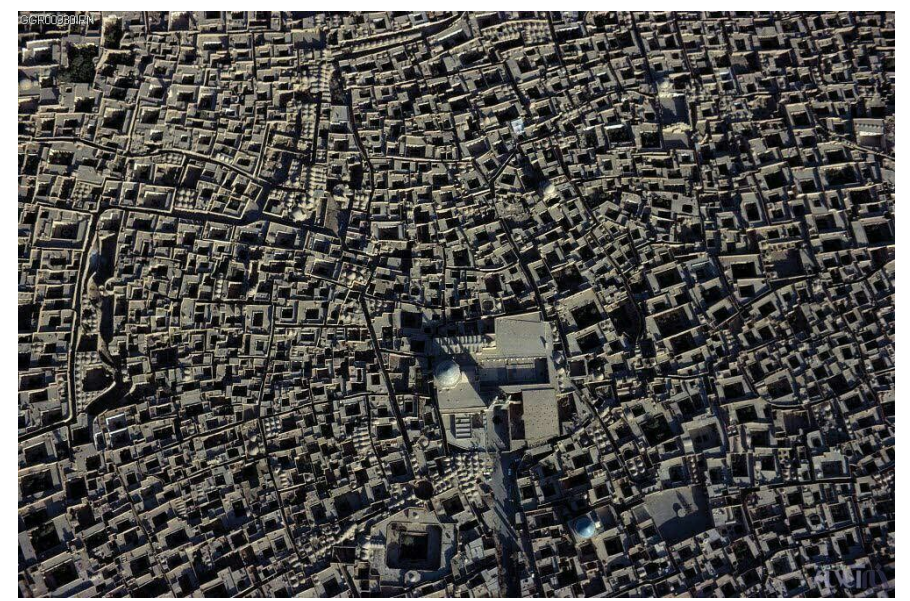

Figure 2-urban fabric of Yazd city 
Figure 3 is a picture from lanes of this fabrics. These lanes were narrow and twisted so winter wind couldn't affect on them so much and in summer there were enough shadow to keep away from the hot sunshine.

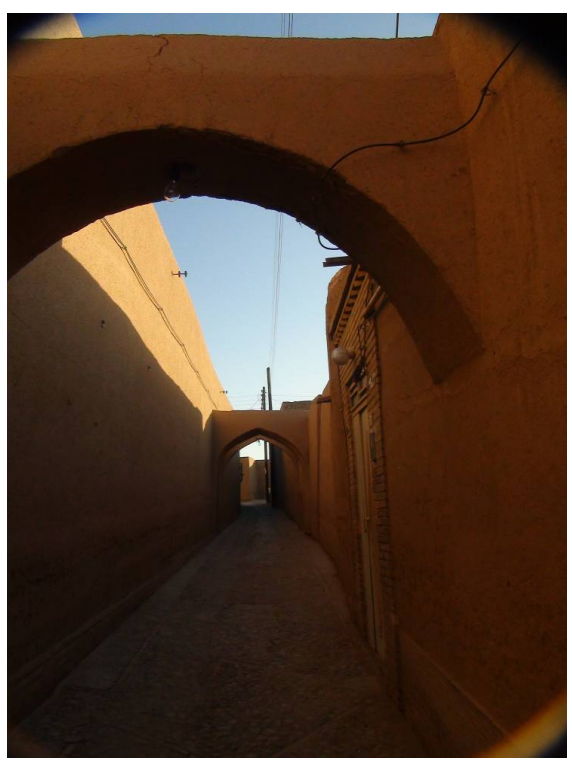

Figure 3- a lane in historical area in Yazd city

\section{3- The characteristic of architecture in hot and dry region:}

Totally the buildings of this region have been erected by mud and brick which have high capacity. In some places which have very hot climate there were also some settlements which were located inside the hills or underground to extend the time of heat transferring extremely. In this way the settlement can utilize the favorite thermal situation of the earth.

In most parts of this region wood is very limited and because of wood scarce the roofs of buildings were constructed by arch and doom by mud and brick. Of course, in semi-arid regions of Iran there are some roofs which were erected in flat form because there was more wood in those area. 


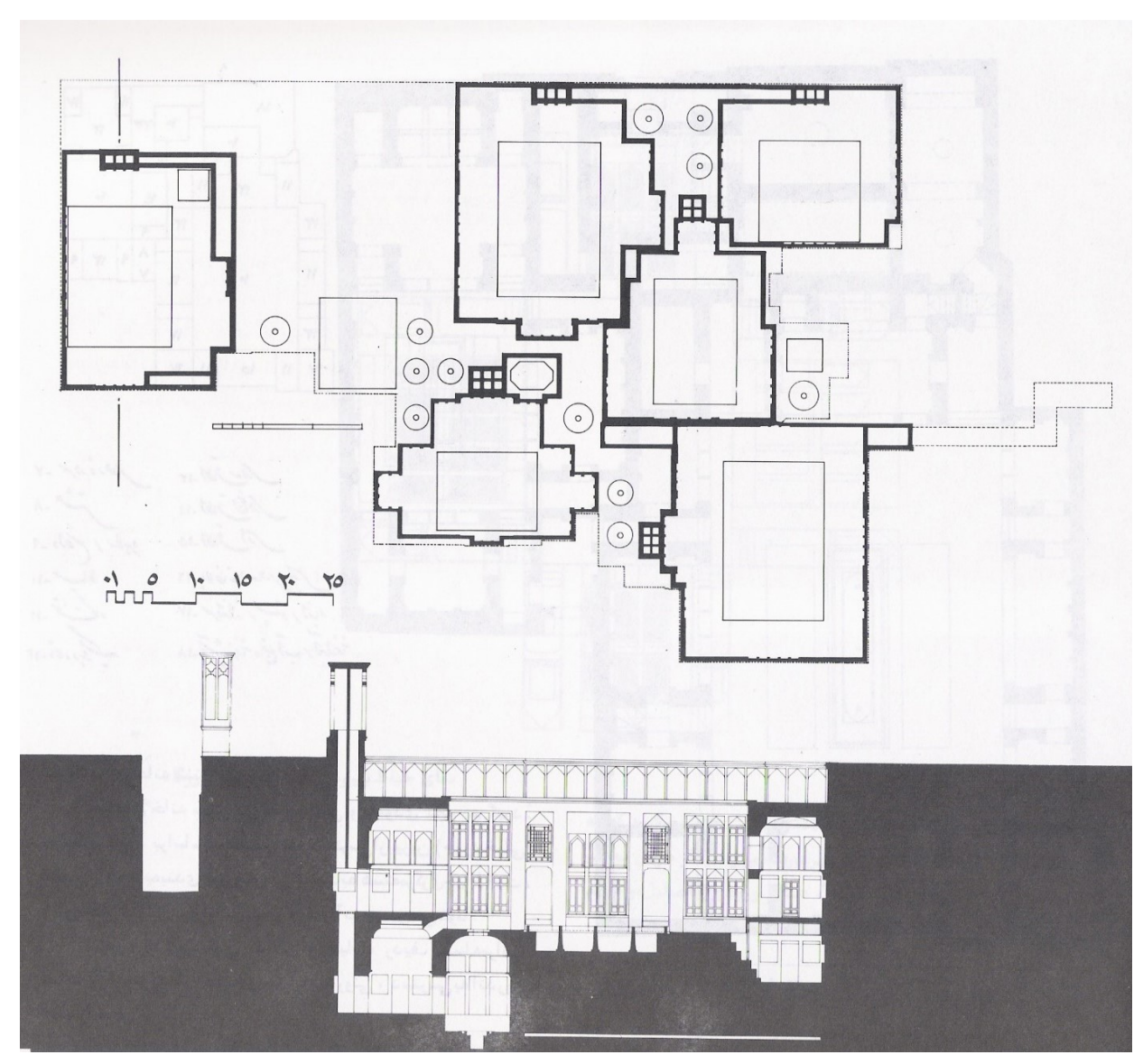

Figure 4- plan and section of traditional houses in Yazd city

To mitigate the observation of heat by the walls the external surface of them was colored in white color.

In hot and dry region, they used wind tower to catch the wind toward the room. This way was the common way for natural ventilation and using the cool wind during the summer in hot and dry region. Using planted atriums (central yards) is one the most important features of these buildings in hot and dry regions. Central yards which concluded trees, pool and planted area were very effective in increasing moisture which were very important in dry region. All of the rooms were opened just to this yard and utilized the shadow and moisture of the yard. The rooms were protected from sand storm and cool winter winds as well by using this technique in design.

Sometimes traditional houses of that area had several central yards and each yard allocated to each member of family (son's family) or servants. 


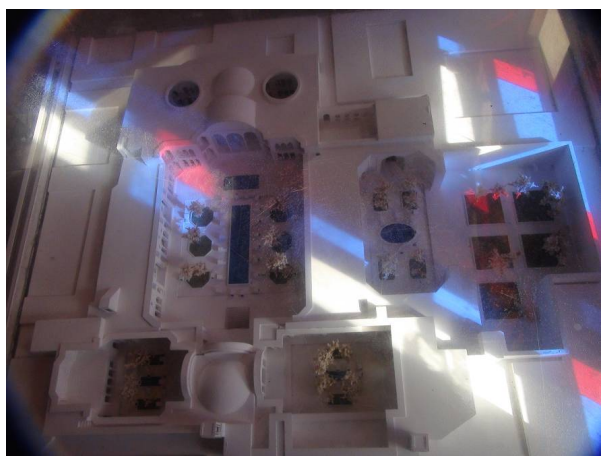

Figure 5- a traditional house in Kashan city with several courtyards

Figure 6 shows a typical central courtyard in an Iranian traditional house which consist pool and trees and other plant to create a cool atmosphere by increasing shadow and moisture in them.

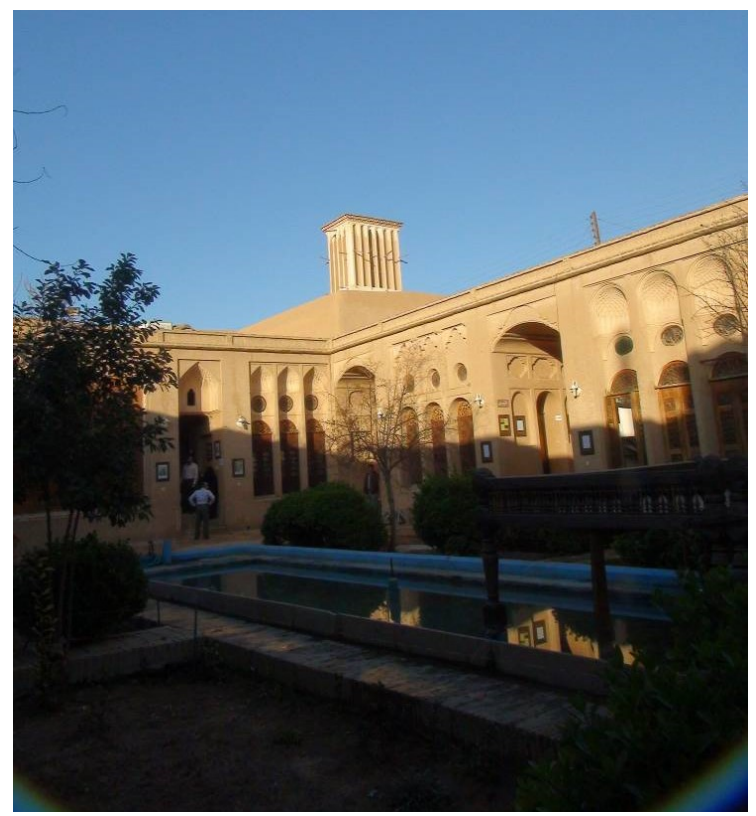

Figure 6- a central courtyard in a traditional courtyard in Yazd city

The orientation of these buildings is toward the south of southern- east. This orientation is the best orientation to control and minimizing the penetrate of the heat of sun.

Using colored window is the other feature of these houses. They use colorful windows for rooms to decrease the heat of sun during the hot days. This technique increased the beauty of the interior room too much (figure 7). 

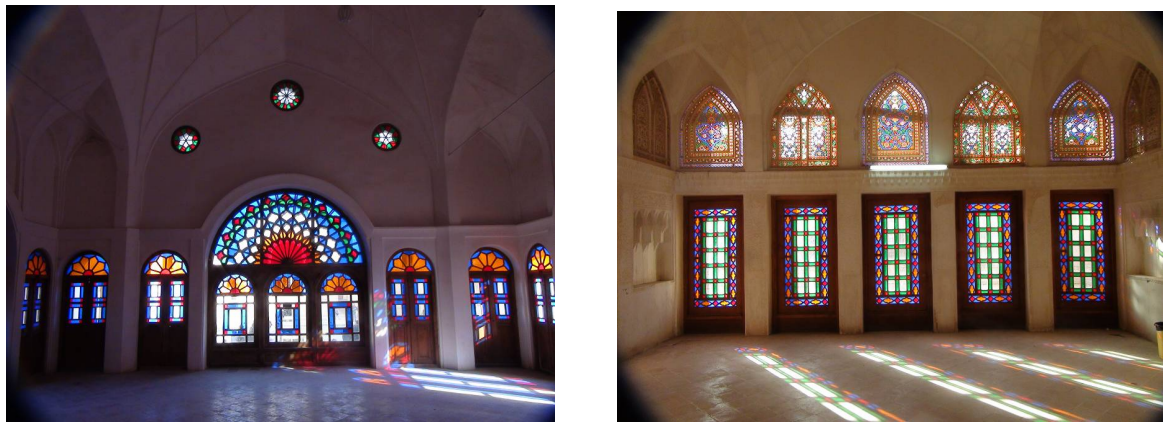

Figure 7- the interior of the room of a traditional house in Kashan city

In most cases the courtyards were entered in the ground to use the thermal capacity of the ground and increasing the shadow of walls as well. They called these yards "Garden pit" (figure 8).

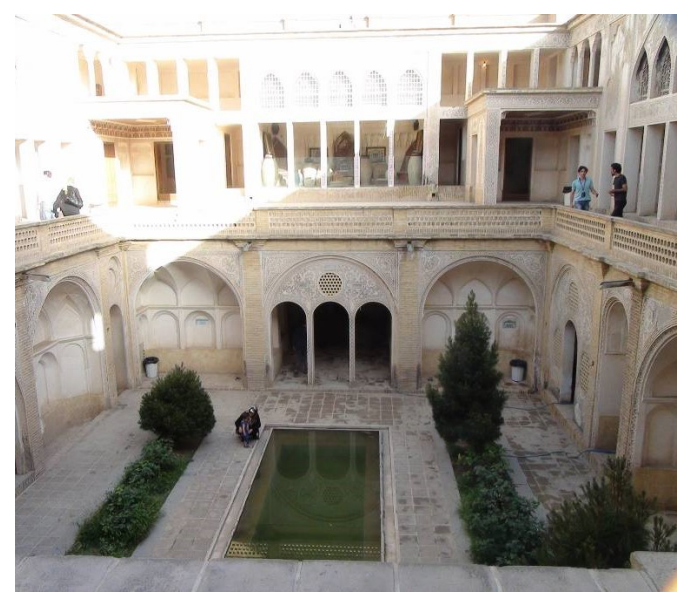

Figure 8- A "garden pit" in a traditional house in Kashan city

\section{1 surveying of some traditional hydraulic structures in historical cities of Iran}

In historical hot cities of Iran there several types of hydraulic structures to serve citizens these structures mostly included bath, water reservoir, ice house, wash house, Payab, water mill.

These elements usually were located along the path of water. In most of cities of Iran, water was earned by Qanats and hydraulic structures were set along the path of water of Qanats.

Figures 9-12 show some hydraulic structures in hot cities of Iran. 


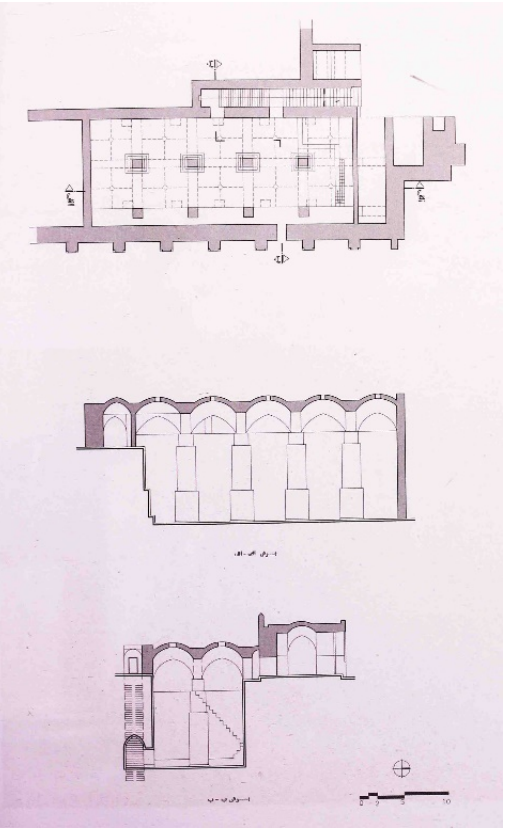

Figure 9- plan and section of a water reservoir in Qazvin city
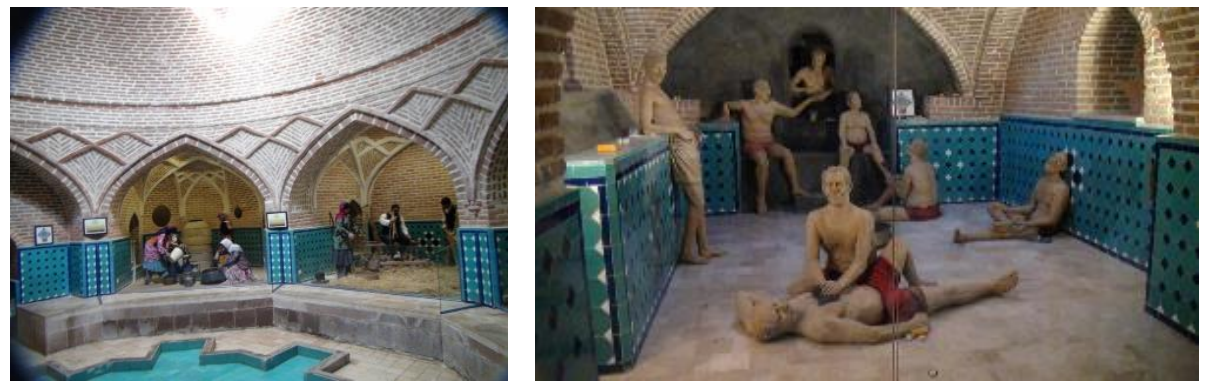

Figure 10- traditional bath in Qazvin city

Payab is a structure which lead to the water of Qanat in underground. Jame mosque (The great mosque) and some important houses had this structure to reach the water of Qanat.

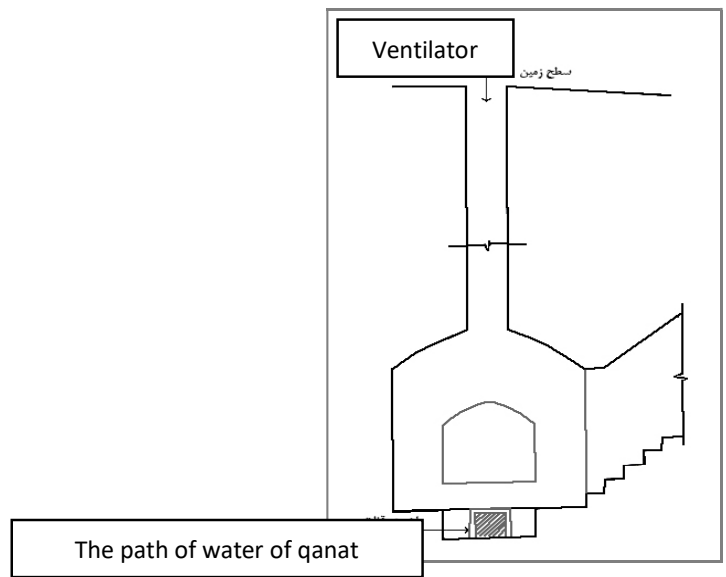

Figure 11- the section of a Payab 


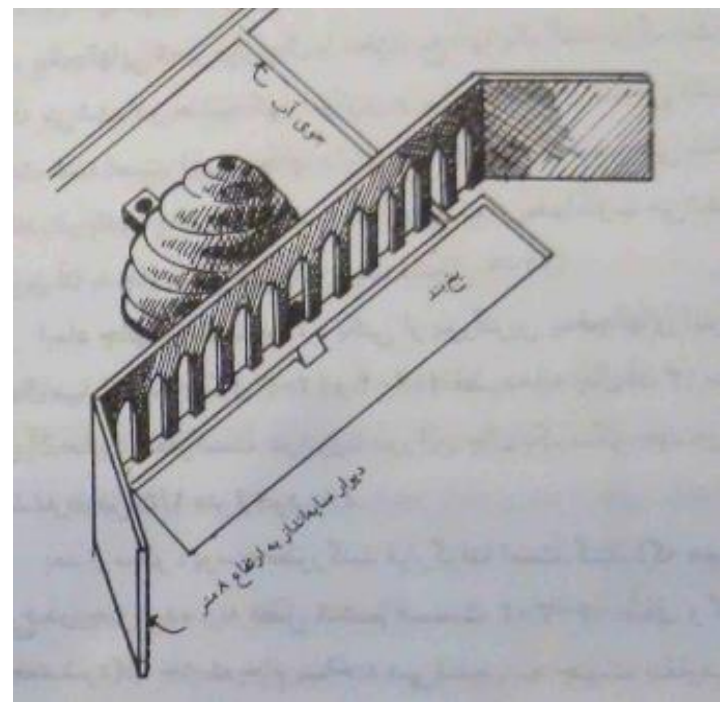

Figure 12- Ice house and its elements

\section{Learning from traditional architecture and urban planning of Iran}

As it was mentioned, in the past Iranian architects used some intellectual ways to be adopted with the harsh and hot climate of that region. These ways were completely adoptable with nature and environment. The buildings were heated and cooled mostly by architectural design techniques. In contrast nowadays we should spend a lot of energy for heating or cooling in the buildings and this waste a lot of nonrenewable energy in cities of Iran. Today buildings should spend a lot of energy because builders don't concern climatic design codes during the construction. Recent buildings in Iran waste a lot of energy in summer and winter both because builders don't use isolation in them.

Of course, reviewing of the features of traditional Iranian houses in hot cities doesn't mean that we should go back to these houses and live in them or built exactly like them.

We studied these houses to use every suitable features of these houses, for example increasing the thermal capacity in the material of recent building can be a good solution against high thermal fluctuation in desert temprature. Increasing shadow in building can be a good way to mitigate the temprature of the building as well.

Using canopy on the top of windows is another practical sulotion to decrease the cooling energy during the day by preventing the direct sunshine to the room to come in.

\section{Conclusion}

Iran has a rich heritage in architecture and urban planning but unfortunately in modern area the quality of architecture and urban planning has been decreasing very much. There are many structural codes for construction but in most cases these codes have been ignored by designers and builders both. For example, there are some codes for energy saving that have some codes about designing in such a way that increasing the energy saving of buildings. These codes including choosing suitable materials and detail to increase the energy saving in buildings and avoiding to waste energy and designing efficient canopies to avoid extremely heating in the rooms. 
It is obvious that we couldn't and shouldn't build exactly like the past. But we can learn some lessons from them. The most important thing is learning how our ancestors were adopted with nature and didn't fight with it. They found some sustainable solutions to create suitable situations in their living spaces.

\section{References:}

1- Ardalan, Nader. Bakhtiar, Lale. (2001). The sense of Unity. T: Shahrokh Hamid. Tehran: Khak

2- Abou Zia, Farhad. Ghezel bash Mohammad Reza. (1989). The Alphabet of the traditional house in Yazd city. The ministry of economy

3- Ghobadian Vahid.(2003). Climatic analysis of the traditional Iranian buildings. Tehran: university of Tehran

4- Khazaee, Hamidreza.(2015) marvelous water structures in Qaen . Mashad : Mahjan.

5- Kheyr Abadi, Masyood. ( 1997). Cities of Iran. Tehran: Nika 